\title{
Case Report: Surgical Management of Radicular Cyst by Root Amputation
}

\author{
Meri A. Hristamyan ${ }^{1 *}$, Veselka P. Hristamyan ${ }^{2}$ \\ ${ }^{I}$ Department of Epidemiology and Disaster Medicine, Faculty of Public Health, Medical University of Plovdiv, \\ Plovdiv, Bulgaria \\ ${ }^{2}$ Clinic of Maxillofacial Surgery, St. George University Hospital, Plovdiv, Bulgaria
}

*Corresponding Author: Meri A. Hristamyan, Department of Epidemiology and Disaster Medicine, Faculty of Public Health, Medical University of Plovdiv, 15A Vassil Aprilov Blvd., Plovdiv, Bulgaria.

\begin{abstract}
This case report presents a 62-year old female patient admitted to the Clinic of Maxillofacial Surgery of St. George University Hospital, Plovdiv, Bulgaria for treatment of a radicular cyst. Due to financial reasons, the patient refuses the initially suggested removal of the bridge structure in the affected area, in which the tooth with the radicular cyst (16) is a bridge carrier. Therefore, extirpation of the cystic formation by removing only the roots of the affected tooth is undertaken. Surgery is performed under local anesthesia, with preparation of two mucoperiosteal flaps, one vestibular and one palatinal. The three roots of tooth 16 are separated, root amputation is performed, and a cystic formation sized $20 \mathrm{~mm}$ by $5 \mathrm{~mm}$, associated with the palatinal root, is extirpated.
\end{abstract}

Keywords: Infected radicular cyst, root amputation, oral surgery

\section{INTRODUCTION}

The cysts in the maxillofacial area are the most common types of cysts in the human body. This is due to both abnormalities in embryonic development and ontogenetic factors, as well as frequent chronic inflammatory processes in this area. The cyst is a pathological cavity in the human body that has its connective tissue sheath, upholstered with epithelium and filled with liquid. Usually this liquid is called cystic fluid and contains cholesterol crystals.

Radicular cysts are the most common cystic lesions affecting the jaw, representing between $55 \%$ to $72 \%$ of all cysts affecting this area [1]. They are usually asymptomatic and mostly diagnosed during routine radiological examinations. Methods of management of radicular cysts include conventional nonsurgical root canal therapy when the lesion is localized, or surgical treatment such as enucleation or decompression in larger cysts [2].

\section{CASE Report}

In 2020, a female patient aged 62, is admitted to the Clinic of Maxillofacial Surgery of St. George University Hospital, Plovdiv, Bulgaria, for treatment of a radicular cyst in the right side of the maxilla. The cyst is found during routine radiological examinations (orthopantomography) and the patient is referred to the clinic (Fig. 1). The patient refuses the initially suggested removal of the bridge structure in the affected area, in which the tooth with the radicular cyst (16) is a bridge carrier. Therefore, the undertaken treatment method is the extirpation of the cystic formation by removing only the roots of the affected tooth (16).

Surgery is performed under local anesthesia, with preparation of two mucoperiosteal flaps, one vestibular and one palatinal (Fig. 2). The three roots of tooth 16 are separated while maintaining the root portion of the tooth. Root amputation is performed (Fig. 3) and a cystic formation sized $20 \mathrm{~mm}$ by $5 \mathrm{~mm}$, associated with the palatinalroot, is extirpated. During manipulation, communication with the maxillary sinus does not occur and the wound is sutured (Fig.4)

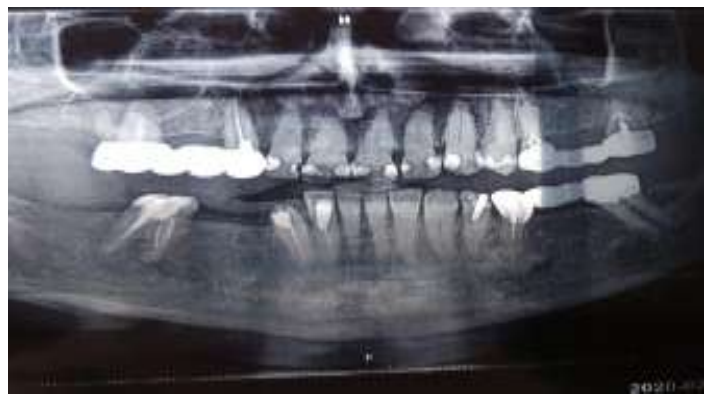

Fig1. Orthopantomography upon admission 


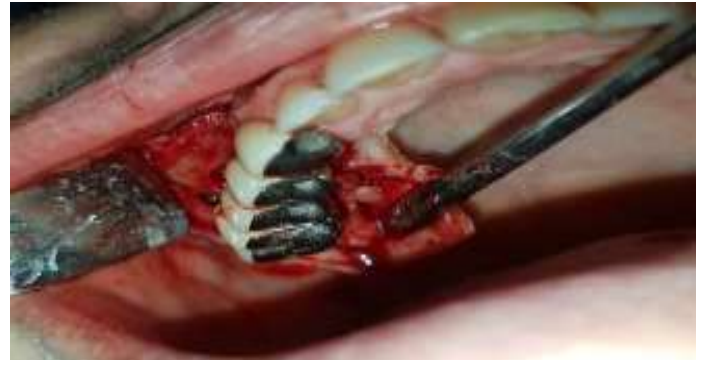

Fig2. Mucoperiosteal flap

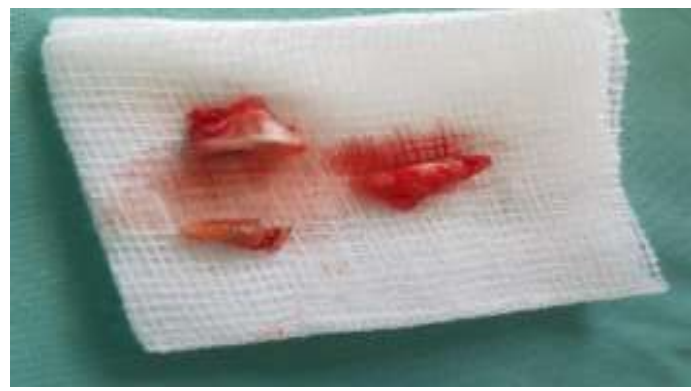

Fig3. Amputated roots of tooth 16

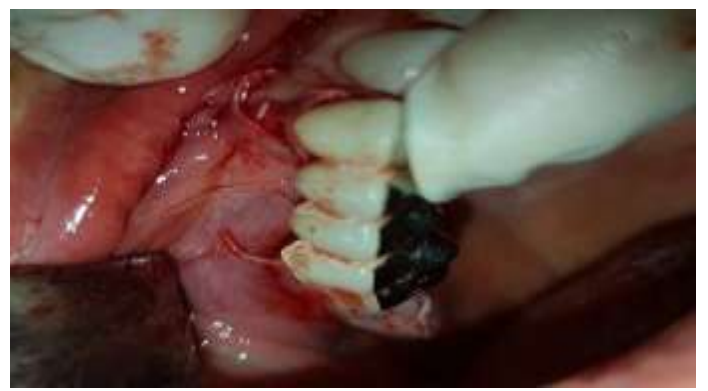

Fig4. Wound suture

\section{DISCUSSION}

The cyst is a pathological cavity in the human body that has its connective tissue sheath, upholstered with epithelium and filled with cystic fluid that contains of cholesterol crystals. With raducular cysts, convergence of the crowns usually accurs, but with no tooth intraorally and radiographically detected in the cyst, which is natural because its development is not related to the tooth, but the result of irregularities in the embryonic development of the jaws. These types of cysts grow expansively, meaning they push the tissues in their path, a major difference from the malignant tumors that destroy tissues in their path. That is why cysts have a bone reactive zone, called "Osteosclerotic shaft", while in tumors sych zone is missing. In addition, the expansive growth answers the question why most of the small cysts are perfectly spherical in shape, and as they grow larger, their shape becomes irregular, usually pear-shaped, due to the different resistance of the tissues. In this regard, the development of cysts in the direction of body cavities, such as the maxillary sinus, is of diagnostic, clinical and, respectively, therapeutic interest [3].

A radicular cyst can only be managed through marsupialisation when it is not attached to the periapical region and is not attached to the teeth. The procedure is known as Partch [3]. In the atrophic mandible of larger cysts, the radicular type is treated by marsupialisation to reduce the size of the cyst, followed by enucleation, to prevent pathological fracture and major deformity after excision, also known as the Partch II or Waldron procedure [4]. Enucleation occurs in the entulsion area when the cyst does not involve the teeth and manifests as a residual cyst. Radicular cysts are treated by enucleation followed by periapical surgery when the cyst includes the periapical area of the teeth and the teeth are rescuable [4].

The indications for periapical surgery are [1]:

- Persistent infection or periapical lesion in the teeth to treat the root canal

- Persistent infection when repeated RCT is not indicated

- Excessive elongation of root canal material

- Perforation that cannot be repaired by pulpal access [5].

Periodic surgery or root surgery is the term for the procedure in which the root canal of the affected teeth is treated and after the cyst enucleation of $3 \mathrm{~mm}$, the apical portion of the root is resected [6]. Accordingly, after the periapical preparation, it expands about $3 \mathrm{~mm}$ into the root canal and is filled with biocompatible and well-sealing material, using a retrograde approach, using ultrasonic nozzles and specialized instruments [1].

\section{CONCLUSiON}

In the presented case of a radicular cyst treatment, because of the patient refusal to the initially suggested removal of the bridge structure in the affected area and the extraction of the affected tooth, root amputation is performed. This is an alternative method to, if necessary, preserve the crown portion of an affected tooth, and successfully extirpate radicular cyst formation.

\section{ACKNOWLEDGMENTS}

The paper was supported by the Ministry of Education and Science, Republic of Bulgaria (National program "Young scientists and postdoctoral students"). 


\section{REFERENCES}

[1] Tsolov R, Firkova E, Chenchev I, Yordanov G, Paecheva P; Bisphosphonate - related osteonecrosis of the jaw: a 3-years retrospective study of frequency and risk factors. Journal of IMAB. 2019 Jul-Sep; 25 (3).

[2] Tsolov R, Firkova E, Yordanov G. Comparative analysis of the healing process after conservative and surgical treatment of Medicamentally Induced Osteonecrosis of the Jaws, Bulgarian Medical Journal, 2019; 2 (21).

[3] Grossman L. Endodontic practice. 11th edition. Philadelphia. 1988; 194-196.
[4] Frederiksen NL. Specialized Radiographic Techniques. In: White SC, Pharoah MJ (eds) Oral Radiology: Principles and Interpratation. 2004; 245-250.

[5] Partsch C. Uber kiefercysten. Deutsche Monatsschrift Fur Zahnheilkunde 1892; 10: 271.

[6] Waldron CA. Cistos e tumores odontogênicos. In: Neville BW, Damm D, Bouquot J, Allen C (eds) Patologia oral \& maxilo facial. Rio de Janeiro: Guanabara Koogan. 1998; 481-527.

Citation: Meri A. Hristamyan, Veselka P. Hristamyan. Case Report: Surgical Management of Radicular Cyst by Root Amputation. ARC Journal of Dental science. 2020; 5(1):5-7. doi:dx.doi.org/10.20431/24560030.0501002 .

Copyright: (C) 2020 Authors. This is an open-access article distributed under the terms of the Creative Commons Attribution License, which permits unrestricted use, distribution, and reproduction in any medium, provided the original author and source are credited. 